\title{
The magnitude of benefit from adding taxanes to anthracyclines in the adjuvant settings of breast cancer: discussion of large trials and meta-analyses
}

\author{
Osama H. Elzaafarany ${ }^{1}$, Atlal Abusanad ${ }^{2}$ \\ ${ }^{1}$ Cancer Management and Research Department, Medical Research Institute-Alexandria University, Alexandria 21561, Egypt. \\ ${ }^{2}$ Faculty of Medicine, King Abdulaziz University Hospital, Jeddah 21589, Saudi Arabia.
}

Correspondence to: Dr. Osama H. Elzaafarany, Cancer Management and Research Department, Medical Research InstituteAlexandria University, Alexandria 21561, Egypt. E-mail: ossama1@alexu.edu.eg

How to cite this article: Elzaafarany $\mathrm{OH}$, Abusanad A. The magnitude of benefit from adding taxanes to anthracyclines in the adjuvant settings of breast cancer: discussion of large trials and meta-analyses. J Cancer Metastasis Treat 2018;4:14.

http://dx.doi.org/10.20517/2394-4722.2017.55

Received: 9 Oct 2017 First Decision: 4 Dec 2017 Revised: 6 Mar 2018 Accepted: 8 Mar 2018 Published: 15 Mar 2018

Science Editor: Godefridus J. Peters Copy Editor: Jun-Yao Li Production Editor: Huan-Liang Wu

\begin{abstract}
The taxanes family of chemotherapy, which includes paclitaxel and docetaxel, has been incorporated in the adjuvant breast cancer treatments since 1990s. Sequential and concurrent use of taxanes was investigated with anthracyclines in many adjuvant early breast cancer randomized clinical trials. Results from taxanes trials showed inconsistent benefits. However, several meta-analyses showed significant survival benefit of adding taxanes. In this review article, data were collected and summarized from eleven large randomized trials and three meta-analyses to show and discuss the magnitude of benefit of taxanes-anthracyclines combination compared to anthracyclines only adjuvant regimens in early breast cancer. This article aims at providing the oncologists with a well-organized, inclusive and updated evidence.
\end{abstract}

Keywords: Breast cancer, adjuvant chemotherapy, taxanes, anthracyclines

\section{INTRODUCTION}

Adjuvant chemotherapy represents an integral part in the care of breast cancer patients. It has been shown that it significantly reduces the risk of recurrence and the risk of death from breast cancer ${ }^{[1]}$. Adjuvant chemotherapy in breast cancer has passed through six main eras; the cyclophosphamide, methotrexate, fluorouracil (CMF)-era, anthracyclines-era, taxanes-era, dose-dense era, combination with targeted therapy era, and recently the individualized use of chemotherapy based on genetic testing. This article focuses on the taxanes-era; discussing the large randomized trials (which included more than 1000 patients) [Table 1] and

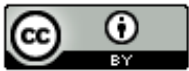

(C) The Author(s) 2018. Open Access This article is licensed under a Creative Commons Attribution 4.0 International License (https://creativecommons.org/licenses/by/4.0/), which permits unrestricted use, sharing, adaptation, distribution and reproduction in any medium or format, for any purpose, even commercially, as long as you give appropriate credit to the original author(s) and the source, provide a link to the Creative Commons license, and indicate if changes were made.

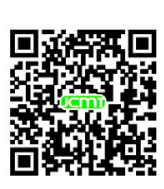


Table 1. The 8 large taxanes trials which compare adjuvant taxanes-anthracyclines to the standard of care regimens: (4 AC, 6 FAC, 6 FEC, and 6 oral-CMF)

\begin{tabular}{|c|c|c|c|c|c|c|c|c|}
\hline Trial name & CALGB 9344 & NSABP-B28 & BCIRG-001 & PACS-01 & E 2197 & GEICAM 9906 & $\begin{array}{l}\text { GEICAM } \\
9805\end{array}$ & AGO \\
\hline Year of publication & 2003 & 2005 & 2005 & 2006 & 2008 & 2008 & 2010 & 2014 \\
\hline Number of patients & 3121 & 3060 & 1480 & 1999 & 2882 & 1246 & 1060 & 2011 \\
\hline Control arm & $\begin{array}{l}4 \times A C \\
\text { (escalading dose } \\
\text { of } A \text { ) }\end{array}$ & $4 \times A C$ & $6 \times F A C$ & $6 \times \mathrm{FEC}$ & $4 \times A C$ & $6 \times \mathrm{FEC}$ & $6 \times F A C$ & $\begin{array}{l}6 \times \text { FEC } \\
\text { or } \\
6 \times \text { CMF-oral }\end{array}$ \\
\hline Taxanes arm & $4 \mathrm{AC} \rightarrow 4 \mathrm{P}$ & $4 \mathrm{AC} \rightarrow 4 \mathrm{P}$ & $6 \times \mathrm{TAC}$ & $\begin{array}{l}3 \mathrm{FEC} \rightarrow 3 \\
\mathrm{D}\end{array}$ & $4 \times$ AT & $\begin{array}{l}4 \mathrm{FEC} \rightarrow 8 \\
\text { weekly } \mathrm{P}\end{array}$ & $6 \times \mathrm{TAC}$ & $4 \mathrm{EC} \rightarrow 4 \mathrm{D}$ \\
\hline Taxanes dose & $\begin{array}{l}\text { Paclitaxel } \\
175 \mathrm{mg} / \mathrm{m}^{2}\end{array}$ & $\begin{array}{l}\text { Paclitaxel } \\
225 \mathrm{mg} / \mathrm{m}^{2}\end{array}$ & $\begin{array}{l}\text { Docetaxel } \\
75 \mathrm{mg} / \mathrm{m}^{2}\end{array}$ & $\begin{array}{l}\text { Docetaxel } \\
100 \mathrm{mg} / \mathrm{m}^{2}\end{array}$ & $\begin{array}{l}\text { Docetaxel } \\
60 \mathrm{mg} / \mathrm{m}^{2}\end{array}$ & $\begin{array}{l}\text { Paclitaxel } \\
100 \mathrm{mg} / \mathrm{m}^{2} / \mathrm{W}\end{array}$ & $\begin{array}{l}\text { Docetaxel } \\
75 \mathrm{mg} / \mathrm{m}^{2}\end{array}$ & $\begin{array}{l}\text { Docetaxel } \\
100 \mathrm{mg} / \mathrm{m}^{2}\end{array}$ \\
\hline $\begin{array}{l}\text { LNs status for eligible } \\
\text { patients }\end{array}$ & Positive & Positive & Positive & Positive & $\begin{array}{l}66 \% \text {-ve } \\
\text { LNs and the } \\
\text { rest are 1-3 } \\
\text { +ve LNs }\end{array}$ & Positive & Negative & $1-3+$ ve LNs \\
\hline $\begin{array}{l}\% \text { of patients completed } \\
\text { full taxanes course }\end{array}$ & $92 \%$ & $75 \%$ & $91 \%$ & $96 \%$ & $94 \%$ & $99.5 \%$ & $94.5 \%$ & $81.2 \%$ \\
\hline $\begin{array}{l}\text { Statistically significant } \\
\text { benefit }\end{array}$ & $\begin{array}{l}\text { DFS } \\
\text { OS }\end{array}$ & DFS & $\begin{array}{l}\text { DFS } \\
\text { OS }\end{array}$ & $\begin{array}{l}\text { DFS } \\
\text { OS }\end{array}$ & Negative & DFS & DSF & $\begin{array}{l}\text { EFS } \\
\text { OS }\end{array}$ \\
\hline $\begin{array}{l}\text { Absolute } \\
\text { 5-year DFS difference }\end{array}$ & $5 \%$ & $4 \%$ & $7 \%$ & $5.2 \%$ & $0 \%$ & $6.4 \%$ & $4.8 \%$ & $\begin{array}{l}\text { 5-year EFS } \\
2.5 \%\end{array}$ \\
\hline $\begin{array}{l}\text { Absolute } \\
\text { 5-year OS difference }\end{array}$ & $3 \%$ & NA & $6 \%$ & $4 \%$ & NA & NA & NA & $1.7 \%$ \\
\hline $\begin{array}{l}\text { Subgroup who get } \\
\text { significant benefit }\end{array}$ & ER -ve & $\begin{array}{l}\text { Not affected } \\
\text { by ER status }\end{array}$ & +ve 1-3 LNs & $\begin{array}{l}\text { +ve } 1-3 \text { LNs } \\
\& \\
\text { age U } 50 \\
\text { years }\end{array}$ & $\begin{array}{l}\text { DFS with } \\
\text { ER/PR -ve } \\
\text { ER+/PR- }\end{array}$ & $\begin{array}{l}\text { ER -ve } \\
\text { Her2 -ve } \\
\text { Also, depend } \\
\text { on LNs status } \\
\text { and tumor size }\end{array}$ & $\begin{array}{l}\text { No } \\
\text { difference } \\
\text { among all } \\
\text { patients' } \\
\text { subsets }\end{array}$ & $\begin{array}{l}\text { ER +ve plus } \\
\text { KI } 67 \text { U } 20 \%\end{array}$ \\
\hline $\begin{array}{l}\text { NF or neutropenia \% } \\
\text { with taxanes arm }\end{array}$ & $\begin{array}{l}\text { Granulocytopenia } \\
\leq 500 \\
\text { was } 16 \%\end{array}$ & NF 3\% & NF $25 \%$ & NF $11.2 \%$ & $\begin{array}{l}\text { Grade III } \\
\text { neutropenia } \\
26 \%\end{array}$ & NF $9.5 \%$ & NF $9.6 \%$ & $\begin{array}{l}\text { NF } 3.7 \% \\
\text { (G-CSF } \\
\text { prophylaxis } \\
\text { was allowed) }\end{array}$ \\
\hline
\end{tabular}

AC: doxorubicin-cyclophosphamide; EC: epirubicin-cyclophosphamide; FAC: doxorubicin-cyclophosphamide-5-fluorouracil; TAC: docetaxel-doxorubicin-cyclophosphamide; FEC: epirubicin-cyclophosphamide-5-fluorouracil; CMF: cyclophosphamide, methotrexate, fluorouracil; OS: overall survival; DFS: disease free survival; EFS: event-free survival; G-CSF: granulocyte-colony stimulating factor; ER: estrogen receptor; PR: progesterone receptor; LN: lymph node; NF: neutropenia with fever; NA: not available

meta-analyses, to provide a well-organized and appealing summary. The primary endpoints of taxanes trials differed, overall survival (OS) is being the primary endpoint in some while disease free survival (DFS) in others. We start by discussing OS trials followed by DFS, as OS is considered the most valuable outcome in adjuvant cancer trials.

\section{RANDOMIZED TRIALS SHOWED SIGNIFICANT OS BENEFIT FROM ADDING TAXANES}

Four large randomized controlled trials showed statistical significant OS benefit from adding taxanes to anthracycles in the adjuvant settings of early-stage breast cancer. Those trials are discussed below.

\section{CALGB-B 9344 trial}

This landmark trial was conducted by the Cancer and Leukemia Group B (CALGB) from USA and published in 2003. It randomized 3121 breast cancer patients with positive axillary lymph nodes (LNs) after surgery to receive 4 cycles of doxorubicin-cyclophosphamide (AC) regimen followed by either 4 cycles of paclitaxel $\left(175 \mathrm{mg} / \mathrm{m}^{2}\right) v s$. placebo. Adding paclitaxel to AC resulted in 5-year DFS of 70\% compared to 65\% in AC only arm, furthermore it resulted in 5 -year OS of $80 \%$ vs. $77 \%$ in AC only arm $^{[2]}$. It concluded that escalating the doxorubicin dose did not add a significant benefit, but adding paclitaxel resulted in a statistical significant advantage in both DFS and OS compared to non-paclitaxel arm. 


\section{BCIRG-001 trial}

The Breast Cancer International Research Group (BCIRG) trial was published in 2005. BCIRG-001 compared 6 cycles of doxorubicin-cyclophosphamide-5-fluorouracil (5FU) regimen (FAC) vs. 6 cycles of docetaxeldoxorubicin-cyclophosphamide (TAC) regimen in 1480 breast cancer patients with positive LNs after surgery. Ninety-one percent of the patients completed the full TAC course despite the fact that there was no routine use of granulocyte-colony stimulating factor (G-CSF) primary prophylaxis. It reported 5-year OS of $87 \%$ in the TAC arm compared to $81 \%$ in the FAC arm $(P=0.008)$, and 5 -year DFS of $75 \%$ in the TAC arm compared to $68 \%$ in the FAC arm $(P=0.001)$. Also, there were $25 \%$ of patients in the TAC arm developed neutropenia with fever (NF) vs. $2 \%$ in the FAC $\mathrm{arm}^{[3]}$.

It examined the concurrent use of taxanes-anthracyclines rather than sequential administration which was the case in both the NSABP and CALGB trials. Docetaxel, the second member in taxanes family was used unlike the CALGB and NSABP trial, which is going to be discussed later.

An update of the BCIRG-001 trial was published in 2013, and showed a maintained DFS and OS advantage, after 10-year of follow-up, in favor of the TAC arm. Ten-year OS was $76 \% v s .69 \%$ in the TAC and FAC arm $(P=0.002)$, respectively. In subgroup analysis, TAC improved DFS relative to FAC irrespective of the nodal, hormone receptor, and HER2 status. Grade 3-4 heart failure occurred in 3\% in the TAC arm vs. $2 \%$ in the FAC arm, and it caused death in 2 patients in the TAC arm and 4 patients in the FAC arm ${ }^{[4]}$.

\section{PACS-01 trial}

This is a French trial that was published in 2006 and randomized 1999 breast cancer patients with positive nodes to 3 cycles of adjuvant docetaxel $\left(100 \mathrm{mg} / \mathrm{m}^{2}\right)$ after 3 cycles of epirubicin-cyclophosphamide-5FU (FEC) regimen (FEC-D arm) compared to 6 cycles adjuvant FEC. Five-year DFS in the FEC-D arm was $78.4 \%$ vs. $73.2 \%$ in the FEC only arm $(P=0.11)$. Five-year OS was $90.7 \%$ in the FEC-D arm compared to $86.7 \%$ in the FEC arm $(P=0.14)$. It is noteworthy that G-CSF primary prophylaxis was not allowed in this trial and grade 3-4 neutropenia was $11.2 \%$ in the FEC-D vs. 8.4\% $(P=0.03)$. Also, cardiac toxicity was less in the FEC-D arm when compared to the FEC arm $(P=0.03)$. Patients with $1-3$ positive nodes as well as patients aged 50 years or more had better DFS in subgroup analyses ${ }^{[5]}$.

\section{WSG-AGO trial}

WSG-AGO Trial was published in 2014 from Germany where it randomized 2011 eligible patients to receive either adjuvant 6 cycles FEC regimen (or oral-cyclophosphamide-epirubicin-5FU, which is also known as the oral-CMF, which was received in $9 \%$ of this arm) vs. 4 cycles of adjuvant $\mathrm{EC}$ followed by 4 cycles docetaxel $100 \mathrm{mg} / \mathrm{m}^{2}$ (EC-D arm). It included only patients with 1-3 positive level I/II axillary LNs (pN1) disease, and the results showed that 5 -year event-free survival (EFS) was $87.3 \%$ in the FEC/CMF arm compared to $89.8 \%$ in the EC-D arm $(P=0.038)$, and 5 -year OS was $92.8 \%$ in the FEC/CMF arm compared to $94.5 \%$ in the EC-D arm $(P=0.034)$. Primary G-CSF prophylaxis was allowed, and NF occurred in $3.7 \%$ in the EC-D arm vs. $2.1 \%$ in the FEC/CMF arm. It was noted that patients with estrogen receptor (ER) positive tumors plus $\mathrm{Ki}-67 \geq 20 \%$ had the most benefit from adding taxanes in subgroup analyses ${ }^{[6]}$.

\section{RANDOMIZED TRIALS SHOWED ONLY SIGNIFICANT DFS BENEFIT FROM ADDING TAXANES}

\section{NSABP-B28 trial}

The National Surgical Adjuvant Breast and Bowel Project (NSABP-B28) trial, which was published in 2005 , is one of the landmark adjuvant taxanes' trials. It included 3060 patients with early breast cancer and positive axillary (LNs), then the eligible patients were randomized to receive either 4 cycles AC (AC arm) or 4 cycles AC followed by 4 cycles paclitaxel (AC-T arm). This trial was characterized by using a higher dose of paclitaxel which is $225 \mathrm{mg} / \mathrm{m}^{2}$ without primary G-CSF prophylaxis. There was a DFS benefit in the AC-T arm compared to the AC arm, where 5-year DFS was $76 \%$ in the AC-T arm compared to $72 \%$ in the AC arm (P 
$=0.007)$. There was no significant OS benefit from adding taxanes to anthracycline according to NSABP-B28 trial. It is noted that only $75 \%$ of the patients in the AC-T arm completed the full AC-T course, and this could be the reason for the absence of OS benefit. It is important to remember that there were 7 deaths which could be attributed to chemotherapy in the AC-T arm. However, it was recorded that only $3 \%$ of the patients in the AC-T arm developed febrile neutropenia, and $18 \%$ had grade III neurotoxicity in the same $\operatorname{arm}^{[7]}$.

\section{GEICAM-9906 trial}

The Spanish Breast Cancer Research Group published its special trial GEICAM-9906 in 2008, and it used weekly paclitaxel regimen, however it used only 8 weeks of paclitaxel instead of 12 weeks. It randomized 1246 node positive patients to two arms; the first one received 6 cycles adjuvant FEC and the second arm received 3 cycles adjuvant FEC followed by 8 cycles of weekly paclitaxel $100 \mathrm{mg} / \mathrm{m}^{2}$ (FEC-P). There was a statistically significant difference in DFS from adding weekly paclitaxel to FEC when compared to adjuvant FEC alone, as 5 -year DFS was $78.5 \%$ in FEC-P compared to $72.1 \%(P=0.006)$. But, this benefit was accompanied by increase in NF of $9.5 \% v s .5 .1 \%$. DFS benefit depended on the number of positive LNs and tumor size, also it was better with HER2 negative patients and patients with ER negative tumors based on subgroup analyses of this trial ${ }^{[8]}$.

\section{GEICAM-9805 trial}

Another Spanish trial (GEICAM-9805) was published in 2010 which investigated the benefit of adding adjuvant taxanes in node-negative breast cancer patients, and its arms were identical to the BCIRG-001 arms. But, unlike the BCIRG trial it allowed primary G-CSF prophylaxis in its TAC arm which greatly declined the rate of NF in contrast to the BCIRG study where the NF risk was high. Interestingly, it showed a significant DFS benefit in node-negative patients. In this study, 1060 node-negative patients were randomized to receive 6 cycles adjuvant FAC vs. 6 cycles adjuvant TAC. The results showed that the 5-year DFS was $90.1 \%$ in TAC arm compared to $85.3 \%$ in the FAC arm $(P=0.03)$. NF occurred in $9.6 \%$ with TAC $v s .2 .3 \%$ in the FAC arm $(P \leq 0.001)$. It is important to note that the overall grade 3-4 toxicity from TAC was significantly higher than those with FAC $(28.2 \% \text { vs. } 17 \% ; P<0.001)^{[9]}$.

\section{RANDOMIZED TRIALS WHICH DID NOT SHOW BENEFIT FROM ADDING TAXANES}

\section{Intergroup trial E-2197}

One of the negative taxanes' trials is the North American Breast Cancer Intergroup Trial (E 2197) that was published in 2008 and compared 4 cycles adjuvant AC to 4 cycles adjuvant concurrent doxorubicin-docetaxel $\left(60 \mathrm{mg} / \mathrm{m}^{2}\right)$ AT-arm. It included 2882 high-risk negative nodes breast cancer patients and those with 1-3 positive nodes. Also, primary G-CSF prophylaxis was not allowed in this trial. The results showed that 5-year DFS was $85 \%$ in both arms of the study $(P=0.78)$, however in subgroup analyses there was a trend of better DFS in patients with ER/progesterone receptor $(\mathrm{PR})$ negative $(P=0.02)$ and those with ER positive/PR negative $(P<0.01)$. Grade 3 neutropenia was $26 \%$ in AT arm vs. $10 \%$ in AC arm $(P<0.05)$. There are some explanations why this trial was negative; one of those possible reasons is that the negative nodes patients constituted $66 \%$ of the study population. Secondly, the lower dose of docetaxel which was $60 \mathrm{mg} / \mathrm{m}^{2}$. Lastly, the short overall taxanes course as it was only 4 cycles of $\mathrm{AT}^{[10]}$.

\section{TACT trial}

The UK-TACT trial, published in 2009, is another example of negative taxanes' trials which did not show a statistically significant benefit of adding taxanes to anthracyclines in adjuvant treatment of breast cancer, and there are two possible explanations for this negative result. The first one is that it included both node positive and node negative patients whereas the most of positive taxanes trials included only patients with positive LNs. The second reason is that the control arm received a long course which is 8 cycles of either FEC regimen or 4 cycles FEC followed by another 4 cycles of CMF, in contrast to both the NSABP and BCIRG trials in which the control arm received only 4 cycles of AC and 6 cycles of FAC respectively ${ }^{[1]}$. Another negative trial was MA-21 trial from Canada, which also included node negative patients and the control arm 
Table 2. The 5-year mortality and recurrence for the Cochrane meta-analysis 2007

\begin{tabular}{lcc}
\hline Cochrane meta-analysis 2007 results & With taxanes & Without taxanes \\
\hline 5-year mortality in low-risk patients & $5 \%$ & $6 \%$ \\
5-year mortality in high-risk patients & $21.6 \%$ & $26 \%$ \\
5-year recurrence in low-risk patients & $11.5 \%$ & $14 \%$ \\
5-year recurrence in high-risk patients & $30.3 \%$ & $36 \%$ \\
Neutropenic fever & $13 \%$ & $0.56 \%$ \\
\hline
\end{tabular}

Table 3. The 8-year mortality and recurrence for the EBCTCG overview 2012

\begin{tabular}{|c|c|c|c|c|}
\hline EBCTCG overview 2012 & With taxanes & Non-taxanes & Absolute difference & $P$ value \\
\hline 8-year mortality & $21.1 \%$ & $23.9 \%$ & $2.8 \%$ & 0.0005 \\
\hline 8-year recurrence & $30.2 \%$ & $34.8 \%$ & $4.0 \%$ & 0.000001 \\
\hline
\end{tabular}

EBCTCG: Early Breast Cancer Trialists' Collaborative Group

was the oral CEF regimen. Besides the fact that it was comparing CEF to a dose-dense taxane containing regimen ${ }^{[12]}$.

\section{META-ANALYSES}

There are three meta-analyses that demonstrated benefit from adding taxanes to anthracyclines in the adjuvant settings of breast cancer. All these meta-analyses confirmed that adding taxanes significantly increases OS compared to anthracylclines-only adjuvant regimens.

The first meta-analysis was from Cochrane data base in $2007^{[13]}$, and it included about 21,000 patients from 12 trials with a median follow-up of 60.4 months. It showed that the hazards ratio (HR) of OS was 0.81 favoring the addition of taxanes $(P<0.00001)$. The HR for DFS was also 0.81 favoring the addition of taxanes $(P<0.00001)$. However, it did not show which patients' subgroup demonstrated more benefit from adding taxanes. Table 2 summarizes the results.

The second meta-analysis came from Italy and was published in $2008^{[14]}$. It included 22,900 patients from 13 trials and it showed a significant DFS and OS benefit from adding taxanes to anthracycline in the adjuvant therapy for breast cancer. The absolute 5-year DFS difference was $5 \%$ between taxanes and non-taxanes adjuvant regimens, and 5-year OS difference was 3\%. What is important in this meta-analysis is that it found that adding taxanes did not result in benefit for patients with ER positive and those with $\geq 4$ positive LNs. It also concluded that sequential administration of adjuvant taxanes-anthracyclines is better than concurrent administration of both agents.

The last and the largest meta-analysis was conducted by the Early Breast Cancer Trialists' Collaborative Group (EBCTCG) ${ }^{[15]}$ and published in 2012. It collected data of 100,000 patients from 123 trials and showed that adding taxanes resulted in a small but significant OS benefit compared to non-taxanes regimens. It showed also that all subgroups of patients had the benefit from adding taxanes. The results are shown in Table 3.

\section{CONCLUSION AND RECOMMENDATIONS}

Several randomized clinical trials were conducted to investigate the role of adding taxanes to anthracyclines. Some of these trials established both OS and DFS, whereas other trials did not show any advantage from adding taxanes. Subsequent meta-analyses confirmed the clinical benefit from adding taxanes to anthracyclines in the adjuvant breast cancer chemotherapy protocols.

There are four trials which showed a statistical significant OS advantage from adding taxanes: BCIRG-001 trial, CALGAB-9344 trial, PACS-01 trial, and AGO trial. The highest OS benefit was reported in the 
BCIRG-001 trial of $6 \%$ at 5 years. BCIRG-001 trial compared adjuvant TAC vs. FAC regimens in node positive early breast cancer patients, with subgroup analysis of patients with 1-3 positive nodes showing the largest OS benefit from adding taxanes. However, the incidence of NF was $25 \%$ in the TAC arm which is considered a limitation against its use. Nonetheless, G-CSF prophylaxis was not allowed in this trial and likely contributed to the high incidence of NF. Therefore, it is reasonable to prescribe G-CSF whenever TAC is considered for adjuvant chemotherapy in breast cancer to minimize NF risk.

Other regimens which were associated with significant OS benefit are 4 cycles of andriamycincyclophosphamide followed by 4 cycles of paclitaxel (AC-P) regimen in CALGAB-9344 trial, 3 cycles of 5FUepirubicin-cyclophosphamide followed by 3 cycles docetaxel (FEC-D) regimen in PACS-01 trial, and 4 cycles of epirubicin-cyclophosphamide followed by 4 cycles docetaxel (EC-D) regimen in AGO trial. Subgroup analyses of each trial demonstrated the following; AC-P regimen was more beneficial to patients with ER negative tumors, whereas the EC-D regimen gave better results for ER positive patients. The FEC-D regimen was better for patients with 1-3 positive LNs and those who aged 50 years or more.

Three randomized trials reported significant DFS with adding taxanes to anthracyclines in the adjuvant settings of breast cancer. These trials are NSABP-B28, GEICAM-9906 and GEICAM-9805. It is noteworthy that most of the taxanes trials were conducted on patient with node-positive disease, whereas 3 trials showed negative results in node-negative patients: UK-TACK trial, MA-21 trial, and E-2197 trial. However, TAC regimen resulted in a significant DFS advantage for node-negative patients in GEICAM-9805 trial. Therefore, TAC regimen might be considered for node-negative breast cancer patient. Another important advantage of TAC regimen over AC-P regimen is that the short overall duration which is only 6 cycles of chemotherapy, whereas AC-P is a total 8 cycles. Moreover, The AC-P regimen which was used in NSABP-B28 trial did not result in a significant OS benefit because of the high dose of Paclitaxel that lead to $25 \%$ of patient did not complete the chemotherapy course.

There were 3 meta-analyses which investigated the role of adding taxanes to anthracyclines in the adjuvant setting of breast cancer, and all reported a significant OS benefit from adding taxanes. EBCTCG metaanalysis, which is the largest meta-analysis in this area, showed that all patient subgroups had a significant improvement of OS from adding taxanes. The Italian meta-analysis showed that adding taxanes was not beneficial to ER-positive patients and those with 4 or more positive axillary LN metastases. Nonetheless, Cochrane database meta-analysis did not report which patient subgroup had the greatest OS benefit from adding taxanes.

The positive impact of adding taxanes to anthracyclines in treating breast cancer can be explained by the different mechanisms of action at both the cellular and molecular levels. Such combination helps to overcome drug resistance of both agents if used separately. Anthracyclines works by intercalating into DNA, disrupting topoisomerase-II-mediated DNA repair and generating free radicals which trigger apoptotic pathways of cell death ${ }^{[16]}$. Whereas, taxanes works by binding to microtubules, preferentially to b-tubulin, and stimulate phosphorylation of b-tubulin which leads to stabilization of microtubules by the prevention of depolymerization. The stabilized microtubules interfere with mitotic spindle formation during the cell division and leads to cell death.

The genes that are involved in the action of doxorubicin at the cellular level are those capable of the oxidation reaction (NADH dehydrogenases, nitric oxide synthases, xanthine oxidase) and those capable of deactivating the free radicals such as glutathione peroxidase, catalase, and superoxide dismutase. Also, genes which are involved in the topoisomerase-II pathway of Doxorubicin action include the enzymes involved in the DNA repair and cell cycle control such as TOP2A, MLH1, MSH2, TP53, and ERCC2 genes. Whereas, the main genes involved in the action of Paclitaxel are the b-tubulin and c-erb 2. However, both anthracyclines- 
taxanes share a common mechanism of drug resistance which may explain the failure of this combination in the adjuvant setting of breast cancer. Multidrug resistance-1/P-glycoprotein over-expression and the breast cancer resistance protein are responsible for resistance to both drug categories. Better understanding of drug resistance may help to optimize such combination.

\section{DECLARATIONS}

\section{Authors' contributions}

Corresponding author/principal investigator, prepares and collects the scientific material of the paper, and writes the first draft of the manuscript: Elzaafarany $\mathrm{OH}$

Co-author, reviews and edits the manuscript: Abusanad A

\section{Financial support and sponsorship}

None.

\section{Conflicts of interest}

There are no conflicts of interest.

\section{Patient consent}

Not applicable.

\section{Ethics approval}

Not applicable.

\section{Copyright}

(c) The Author(s) 2018.

\section{REFERENCES}

1. Early Breast Cancer Trialists' Collaborative Group (EBCTCG). Effects of chemotherapy and hormonal therapy for early breast cancer on recurrence and 15-year survival: an overview of the randomised trials. Lancet 2005;365:1687-717.

2. Henderson IC, Berry DA, Demetri GD, Cirrincione CT, Goldstein LJ, Martino S, Ingle JN, Cooper MR, Hayes DF, Tkaczuk KH, Fleming G, Holland JF, Duggan DB, Carpenter JT, Frei E 3rd, Schilsky RL, Wood WC, Muss HB, Norton L. Improved outcomes from adding sequential paclitaxel but not from escalating doxorubicin dose in an adjuvant chemotherapy regimen for patients with node-positive primary breast cancer. J Clin Oncol 2003;21:976-83.

3. Martin M, Pienkowski T, Mackey J, Pawlicki M, Guastalla JP, Weaver C, Tomiak E, Al-Tweigeri T, Chap L, Juhos E, Guevin R, Howell A, Fornander T, Hainsworth J, Coleman R, Vinholes J, Modiano M, Pinter T, Tang SC, Colwell B, Prady C, Provencher L, Walde D, Rodriguez-Lescure A, Hugh J, Loret C, Rupin M, Blitz S, Jacobs P, Murawsky M, Riva A, Vogel C; Breast Cancer International Research Group 001 Investigators. Adjuvant docetaxel for node-positive breast cancer. N Engl J Med 2005;352:2302-13.

4. Mackey JR, Martin M, Pienkowski T, Rolski J, Guastalla JP, Sami A, Glaspy J, Juhos E, Wardley A, Fornander T, Hainsworth J, Coleman R, Modiano MR, Vinholes J, Pinter T, Rodríguez-Lescure A, Colwell B, Whitlock P, Provencher L, Laing K, Walde D, Price C, Hugh JC, Childs BH, Bassi K, Lindsay MA, Wilson V, Rupin M, Houé V, Vogel C; TRIO/BCIRG 001 investigators. Adjuvant docetaxel, doxorubicin, and cyclophosphamide in nodepositive breast cancer: 10-year follow-up of the phase 3 randomised BCIRG 001 trial. Lancet Oncol 2013;14:72-80.

5. Roché H, Fumoleau P, Spielmann M, Canon JL, Delozier T, Serin D, Symann M, Kerbrat P, Soulié P, Eichler F, Viens P, Monnier A, Vindevoghel A, Campone M, Goudier MJ, Bonneterre J, Ferrero JM, Martin AL, Genève J, Asselain B. Sequential adjuvant epirubicinbased and docetaxel chemotherapy for node-positive breast cancer patients: the FNCLCC PACS 01 Trial. J Clin Oncol 2006;24:5664-71.

6. Nitz U, Gluz O, Huober J, Kreipe HH, Kates RE, Hartmann A, Erber R, Moustafa Z, Scholz M, Lisboa B, Mohrmann S, Möbus V, Augustin D, Hoffmann G, Weiss E, Böhmer S, Kreienberg R, Du Bois A, Sattler D, Thomssen C, Kiechle M, Jänicke F, Wallwiener D, Harbeck N, Kuhn W. Final analysis of the prospective WSG-AGO EC-Doc versus FEC phase III trial in intermediate-risk (pN1) early breast cancer: efficacy and predictive value of Ki67 expression. Ann Oncol 2014;25:1551-7.

7. Mamounas EP, Bryant J, Lembersky B, Fehrenbacher L, Sedlacek SM, Fisher B, Wickerham DL, Yothers G, Soran A, Wolmark N. Paclitaxel after doxorubicin plus cyclophosphamide as adjuvant chemotherapy for node-positive breast cancer: results from NSABP B-28. J Clin Oncol 2005;23:3686-96.

8. Martín M, Rodríguez-Lescure A, Ruiz A, Alba E, Calvo L, Ruiz-Borrego M, Munárriz B, Rodríguez CA, Crespo C, de Alava E, López García-Asenjo JA, Guitián MD, Almenar S, González-Palacios JF, Vera F, Palacios J, Ramos M, Gracia Marco JM, Lluch A, Alvarez I, 
Seguí MA, Mayordomo JI, Antón A, Baena JM, Plazaola A, Modolell A, Pelegrí A, Mel JR, Aranda E, Adrover E, Alvarez JV, García Puche JL, Sánchez-Rovira P, Gonzalez S, López-Vega JM; GEICAM 9906 Study Investigators. Randomized phase 3 trial of fluorouracil, epirubicin, and cyclophosphamide alone or followed by paclitaxel for early breast cancer. J Natl Cancer Inst 2008;100:805-14.

9. Martín M, Seguí MA, Antón A, Ruiz A, Ramos M, Adrover E, Aranda I, Rodríguez-Lescure A, Grosse R, Calvo L, Barnadas A, Isla D, Martinez del Prado P, Ruiz Borrego M, Zaluski J, Arcusa A, Muñoz M, López Vega JM, Mel JR, Munarriz B, Llorca C, Jara C, Alba E, Florián J, Li J, López García-Asenjo JA, Sáez A, Rios MJ, Almenar S, Peiró G, Lluch A; GEICAM 9805 Investigators. Adjuvant docetaxel for high-risk, node-negative breast cancer. N Engl J Med 2010;363:2200-10.

10. Goldstein LJ, O'Neill A, Sparano JA, Perez EA, Shulman LN, Martino S, Davidson NE. Concurrent doxorubicin plus docetaxel is not more effective than concurrent doxorubicin plus cyclophosphamide in operable breast cancer with 0 to 3 positive axillary nodes: North American Breast Cancer Intergroup Trial E 2197. J Clin Oncol 2008;26:4092-9.

11. Ellis P, Barrett-Lee P, Johnson L, Cameron D, Wardley A, O’Reilly S, Verrill M, Smith I, Yarnold J, Coleman R, Earl H, Canney P, Twelves C, Poole C, Bloomfield D, Hopwood P, Johnston S, Dowsett M, Bartlett JM, Ellis I, Peckitt C, Hall E, Bliss JM; TACT Trial Management Group; TACT Trialists. Sequential docetaxel as adjuvant chemotherapy for early breast cancer (TACT): an open-label, phase III, randomised controlled trial. Lancet 2009;373:1681-92.

12. Burnell M, Levine MN, Chapman JA, Bramwell V, Gelmon K, Walley B, Vandenberg T, Chalchal H, Albain KS, Perez EA, Rugo H, Pritchard K, O'Brien P, Shepherd LE. Cyclophosphamide, epirubicin, and fluorouracil versus dose-dense epirubicin and cyclophosphamide followed by paclitaxel versus doxorubicin and cyclophosphamide followed by paclitaxel in node-positive or high-risk node-negative breast cancer. J Clin Oncol 2010;28:77-82.

13. Ferguson T, Wilcken N, Vagg R, Ghersi D, Nowak AK. Taxanes for adjuvant treatment of early breast cancer. Cochrane Database Syst Rev 2007;(4):CD004421.

14. De Laurentiis M, Cancello G, D’Agostino D, Giuliano M, Giordano A, Montagna E, Lauria R, Forestieri V, Esposito A, Silvestro L, Pennacchio R, Criscitiello C, Montanino A, Limite G, Bianco AR, De Placido S. Taxane-based combinations as adjuvant chemotherapy of early breast cancer: a meta-analysis of randomized trials. J Clin Oncol 2008;26:44-53.

15. Early Breast Cancer Trialists' Collaborative Group (EBCTCG); Peto R, Davies C, Godwin J, Gray R, Pan HC, Clarke M, Cutter D, Darby S, McGale P, Taylor C, Wang YC, Bergh J, Di Leo A, Albain K, Swain S, Piccart M, Pritchard K. Comparisons between different polychemotherapy regimens for early breast cancer: meta-analyses of long-term outcome among 100,000 women in 123 randomised trials. Lancet 2012;379:432-44.

16. Thorn CF, Oshiro C, Marsh S, Hernandez-Boussard T, McLeod H, Klein TE, Altman RB. Doxorubicin pathways: pharmacodynamics and adverse effects. Pharmacogenet Genomics 2011;21:440-6. 